\title{
Vulvovaginitis infantil
}

\author{
R. Ortiz Movillaa, B.Acevedo Martín ${ }^{b}$ \\ aServicio de Pediatría. Hospital Universitario de Getafe. Getafe, Madrid. España. \\ bServicio de Ginecología y Obstetricia. Fundación Jiménez Díaz. Madrid. España.
}

Fecha de publicación en Internet: 17 de noviembre de 2011

\section{Resumen}

La vulvovaginitis es el problema ginecológico más frecuente en las niñas prepúberes, favorecido por la menor protección del introito vaginal a los agentes externos y la presencia de factores anatómicos (proximidad del ano, labios mayores y menores menos desarrollados, etc.) y hormonales (hipoestrogenismo). A esto se suma el efecto de productos irritantes locales y la coexistencia en ocasiones de malos hábitos higiénicos. La mayoría de las vulvovaginitis en las niñas son inespecíficas, aunque en un porcentaje variable pueden aislarse bacterias patógenas específicas (entéricas, respiratorias, o de transmisión sexual), o ser secundarias a otros procesos como oxiurasis o cuerpos extraños intravaginales.

En el presente artículo analizaremos la etiología, la patogénesis, la clínica y el manejo de esta entidad en la infancia, y realizaremos algunas consideraciones clínicas y microbiológicas sobre distintos cuadros con etiología específica.

Palabras clave: Vulvitis. Vaginitis. Vulvovaginitis. Premenarquia.

\section{Child vulvovaginitis}

Abstract

Vulvovaginitis is the most common gynecological problem in prepubertal girls, helped by their lower introitus protection to external agents and the presence of anatomical (proximity of anus, less developed minor and major labia,...) and hormonal factors (low estrogen concentration). This is added to the effect of local irritants and sometimes co-existence of poor hygiene. Most vulvovaginitis in girls are nonspecific, although specific pathogenic bacteria (enteric, respiratory, or sexually transmitted) can be isolated and they can be also secondary to other causes as oxiurasis, or intravaginal foreign bodies. In this article we will analyze the etiology, pathogenesis, clinical features and management of this disorder in childhood, and we will have some clinical and microbiological considerations of different diseases with specific etiology.

Key words: Vulvitis. Vaginitis. Vulvovaginitis. Premenarcheal.

Roberto Ortiz Movilla, rortizmovilla@telefonica.net

Los autores declaran no presentar conflictos de intereses en relación con la preparación y publicación de este artículo. 


\section{Introducción}

Generalmente, la vulvovaginitis se considera el problema ginecológico más frecuente en niñas prepuberales, aunque su incidencia es desconocida ${ }^{1-5}$. En la práctica clínica, los términos vulvitis, vaginitis y vulvovaginitis se usan indistintamente para referirse a las inflamaciones del tracto genital femenino externo que cursan habitualmente con distintos grados de eritema, prurito, disuria, sangrado o secreción vaginal. En la niña prepuberal existen condiciones anatómicas, fisiológicas e higiénicas diferentes a la adolescente y a la mujer adulta que la hacen especialmente susceptible a este cuadro. Aunque la mayoría de las vulvovaginitis en este grupo de edad son inespecíficas y secundarias a malos hábitos higiénicos, irritantes locales o flora mixta bacteriana, en un porcentaje variable pueden aislarse bacterias patógenas específicas. La presencia de oxiuros, cuerpos extraños vaginales, hongos o infecciones de transmisión sexual, aunque con menos frecuencia, también es en ocasiones responsable de la aparición de esta entidad y debe ser investigada, sobre todo en los casos de vulvovaginitis de repetición o en aquellos casos refractarios al tratamiento habitual.
Etiología y patogénesis. Clínica

La recién nacida tiene la vagina estrogenizada, con una secreción mucosa rica en glóbulos rojos, situación que dura entre 2-3 semanas. Posteriormente, el epitelio hipoestrogénico de las niñas preadolescentes constituye el factor fundamental que hace a la mucosa vaginal susceptible a la infección en este grupo de edad ${ }^{3,5}$. Esta mucosa es delgada, con poco epitelio estratificado y tiene un $\mathrm{pH}$ alcalino que la hace más sensible a la invasión por bacterias patógenas. Otros factores predisponentes en niñas son la menor protección del introito vaginal, debido al escaso desarrollo de los labios mayores y menores, la ausencia de vello pubiano, y la presencia de un himen delgado y amplio. La proximidad anatómica del recto y la vulva, los malos hábitos higiénicos con un aseo genital inadecuado, los productos irritantes locales y la manipulación o la actividad crónica masturbatoria que en ocasiones se puede ver en estas niñas, también son factores favorecedores de esta patología.

La cuestión más importante en el manejo de la vulvovaginitis infantil es determinar si la bacteria aislada en la secreción vaginal de la niña afectada es la causa de los síntomas o forma parte de la flora vaginal habitual. Esta microflora vaginal de las niñas prepuberales no está bien defi- 
nida, pues se han cultivado diferentes microorganismos en los distintos estudios realizados, existiendo disparidad en los hallazgos encontrados ${ }^{6-8}$. Entre las bacterias más aisladas se encuentran distintas especies de anaerobios, así como difteroides, lactobacilos, enterococos, Staphylococcus epidermidis o Streptotoccus viridans. Otros autores encuentran también enterobacterias como Escherichia coli en la flora vaginal de niñas asintomáticas y demuestran que la microflora de estas es similar a la que tienen las niñas sintomáticas, aislándose en más ocasiones anaerobios y $S$. viridans en niñas sin sintomatología, y Staphylococcus aureus y Streptococcus pyogenes en niñas con vulvitis². Además de estos gérmenes, la presencia de otra flora entérica o respiratoria (Haemophilus influenzae, Moraxella catarrhalis, Shigella sp., etc.) se ha objetivado en niñas con sintomatología y es la causa más frecuente de vulvovaginitis específica en este grupo de edad. En la infancia, la infección comienza en la vulva, con diseminación secundaria a la vagina, mientras que en la adolescencia, y sobre todo con el inicio de la actividad sexual, la afectación primaria es vaginal ${ }^{2}$.

Los síntomas más frecuentes en la vulvovaginitis infantil son la secreción vaginal, el eritema vulvar, la disuria y el pru- rito $^{1-4,9-11}$. Se deben investigar las características físicas del flujo vaginal (color, cantidad, olor, consistencia y duración), pues en ocasiones nos orientarán hacia un cuadro específico. En el examen físico, además de la presencia de secreción purulenta, se pueden apreciar signos de inflamación (eritema del introito), así como signos de excoriación del área genital por rascado. En la mayoría de las ocasiones no se necesitan estudios microbiológicos si la clínica es leve, recomendándose un cultivo de la secreción vaginal si existe flujo purulento franco, sintomatología importante o cuadros de repetición.

\section{Vulvovaginitis inespecífica}

Según diversos estudios, solo un tercio de los casos de las vulvovaginitis en la infancia es producido por bacterias específicas, siendo la mayoría de los casos a esta edad vulvovaginitis inespecíficas secundarias a estímulos físicos o químicos con flora bacteriana mixta en los aislamientos microbiológicos ${ }^{1-3}$. Hay autores que incluso argumentan que esta entidad debería considerarse una variante de dermatitis atópica, ya que algunas niñas son especialmente sensibles a una serie de irritantes, como jabones, mala higiene o ropa ajustada, y el prurito vulvar sería la manifestación de esta dermatitis ${ }^{10}$. Tí- 
picamente, en estas vulvovaginitis el flujo es mucoide, no purulento, de pequeña cuantía e inodoro². En la mayoría de los casos no se precisa tratamiento antibiótico sistémico, y la correcta aplicación de una serie de normas higiénicas llevarán a la mejoría del cuadro clínico. Estas normas son:

- Evitar mallas, leotardos o medias apretadas.

- Evitar pijamas que no permitan la circulación del aire durante la noche (mejor camisón).

- Cambio frecuente de ropa interior. Realizar un doble aclarado en esta ropa para evitar irritantes residuales tras el lavado habitual.

- Revisar la correcta higiene de la niña. Se debe prestar especial atención a la limpieza de la zona anal tras la defecación, que siempre debe ser de adelante a atrás, para evitar la introducción de bacterias patógenas o material fecal en la zona vulvovaginal.

- Baño diario en agua tibia sin jabón irritante de la zona vaginal. En ocasiones, se puede utilizar productos antisépticos o cremas protectoras con óxido de zinc especialmente diseñados para esa área.

- Si la vulva está muy eritematosa o inflamada, son de utilidad la aplica- ción de compresas con agua fría, y el uso de algún emoliente que ayude a proteger la piel y la mucosa de la zona.

Estas técnicas generalmente llevan a la resolución del cuadro en dos o tres semanas. Si los síntomas continúan, se debe investigar la posibilidad de un cuerpo extraño en el área vaginal o la existencia de una infección específica, recogiéndose muestras para su estudio microbiológico. En raras ocasiones, si la sintomatología es persistente y hasta la llegada del resultado microbiológico, se puede realizar tratamiento antibiótico oral de forma empírica con amoxicilina-clavulánico, dirigido al S. pyogenes y $\mathrm{H}$. influenzae, bacterias patógenas más frecuentemente aisladas en casos de vulvovaginitis bacteriana como veremos más adelante ${ }^{4}$.

\section{Infecciones específicas}

\section{Oxiurasis}

Aunque los oxiuros no residen en la vulva, las hembras dejan sus huevos en la zona perianal durante la noche y pueden ascender desde el ano al introito vulvar y causar intenso prurito nocturno. Las niñas con episodios recurrentes de picor perianal o vulvar, especialmente si sucede por la noche, deben ser estudiadas para descartar esta infestación y/o 
tratadas empíricamente con mebendazol o pamoato de pirantel ${ }^{3}$.

\section{Flora entérica o respiratoria}

En ocasiones, las niñas pueden pasar flora respiratoria desde la nariz o la faringe al área vulvar. Los patógenos respiratorios que producen esta patología incluyen $S$. pyogenes, $S$. aureus, $H$. influenzae, S. pneumoniae o Neisseria meningitidis. Aunque inicialmente se consideró al $H$. influenzae como la bacteria más frecuentemente implicada en estos casos de vulvovaginitis bacteriana específica, la introducción de la vacunación universal frente a este germen ha hecho que en los últimos años el S. pyogenes sea el responsable de la mayoría de vulvovaginitis bacterianas específicas ${ }^{1-9}$. La mitad de las niñas afectadas por esta bacteria tienen historia personal o familiar de faringoamigdalitis, previsiblemente causada por este patógeno, aunque en ocasiones también se han implicado serotipos de S. pyogenes causantes de impétigo y no de amigdalitis ${ }^{1}$. Generalmente se presenta de forma súbita, con flujo seropurulento, prurito, disuria, eritema e inflamación vulvar². También se han descrito cuadros de vulvovaginitis causados por gérmenes entéricos como Shigella sp. o Yersinia sp., que suelen producir un flujo vaginal mucopurulento frecuentemente acompañado de diarrea ${ }^{1,2}$. Por tanto, y para investigar la etiología específica del cuadro, se deben obtener estudios microbiológicos en casos de flujo vaginal persistente o purulento, y la antibioterapia a utilizar dependerá del organismo aislado: amoxicilina o penicilina $\mathrm{V}$ en caso de $\mathrm{S}$. pyogenes, y amoxicilina-clavulánico en caso de $\mathrm{H}$. influenzae productor de betalactamasas.

\section{Candidiasis}

Aunque la vulvovaginitis por cándida es rara en la niña prepúber, la colonización por esta levadura ocurre en un 3-4\% de las niñas y debe sospecharse una etiología candidiásica ante la presencia de leucorrea no maloliente con prurito en edad puberal, especialmente en niñas con factores de riesgo (inmunosupresión, tratamiento antibiótico reciente, diabetes, etc.). También es frecuente la dermatitis del pañal sobreinfectada por cándida en niñas que usan todavía pañales, que cursa con el característico rash perineal eritematoso, con lesiones satélites. El tratamiento consistirá en la aplicación tópica de pomadas o óvulos de derivados imidazólicos (clotrimazol, fluconazol) o nistatina ${ }^{1,2}$.

\section{Enfermedades de transmisión sexual}

Algunas infecciones de transmisión sexual se pueden presentar con flujo vagi- 
nal aumentado, y típicamente son secundarias a abuso sexual. En un estudio de 1538 niñas que habían padecido estos abusos sexuales, los gérmenes más frecuentemente implicados fueron Neisseria gonorrhoeae $(2,8 \%)$, Chlamydia trachomatis $(1,2 \%)$, virus del papiloma humano (VPH) (1,2\%), Treponema paIlidum $(0,1 \%)$ y Herpes simplex $(0,1 \%)^{12}$. La vulvovaginitis gonocócica raramente es asintomática y se presenta generalmente con un flujo profuso, inodoro, verde-mucoso, En casos más graves, y generalmente en mujeres adolescentes con actividad sexual, se puede manifestar como enfermedad pélvica inflamatoria, uretritis o endocervicitis ${ }^{13}$. En todas las niñas prepúberes que hayan superado el periodo neonatal (donde la infección puede tener un origen vertical), y en las adolescentes sin actividad sexual que presenten una infección gonocócica, debe considerarse que se ha producido abuso sexual a menos que se demuestre lo contrario, aunque excepcionalmente se han descrito casos de enfermedad gonocócica por exposición doméstica al germen ${ }^{14}$. Debido a la prevalencia de $N$. gonorrhoeae resistente a la penicilina, se recomienda una cefalosporina de amplio espectro, como la ceftriaxona, como tratamiento inicial para los pacientes de todas las edades. El diagnóstico de una vulvovaginitis por gonococo debería inducir a investigar otras enfermedades de transmisión sexual como la sífilis, la hepatitis $B$, la infección por el virus de la inmunodeficiencia humana, o la infección por C. trachomatis. Esta infección es la enfermedad de transmisión sexual más frecuente en adolescentes y adultos jóvenes, y puede provocar vulvovaginitis poco sintomática en niñas prepúberes víctimas de abuso sexual. No hay que olvidar que la infección asintomática adquirida en el momento del parto en hijas de madres portadoras puede persistir hasta tres años. El diagnóstico definitivo de la infección por $C$. trachomatis puede establecerse aislando el microorganismo en medios de cultivo que contengan células epiteliales, pues es un patógeno intracelular obligado, aunque los nuevos métodos de amplificación de ácidos nucleícos en orina (PCR y ligasa) son más sensibles que el cultivo celular y se recomiendan de primera elección por algunos expertos ${ }^{15}$. El tratamiento de la infección genital infantil en niñas menores de 12 años puede realizarse con eritromicina o azitromicina, pudiéndose utilizar la doxiciclina en niñas de mayor edad ${ }^{15,16}$.

Las infecciones por Trichomonas vaginalis suelen ser asintomáticas, pero pueden producir vulvovaginitis con flujo vaginal amarillo pálido, grisáceo o verdoso, 
en ocasiones con hemorragias puntiformes en la vagina y el cuello del útero que también deben sugerir abuso sexual si se presentan en niñas prepúberes². El diagnóstico se establece generalmente examinando preparaciones en fresco del flujo vaginal y visualizando este protozoo flagelado. El metronidazol es el fármaco de elección para el tratamiento de esta patología $a^{17}$.

Los virus Herpes simplex 1 y 2 también pueden producir enfermedad genital. Aunque la transmisión perinatal se ha descrito como causa de herpes genital en la infancia, la infección ocurre principalmente tras contacto sexual, lo cual debe ser investigado en niñas prepúberes. Clínicamente cursa con prurito vaginal, disuria y dolor local, objetivándose vesículas agrupadas con base eritematosa como hallazgo fundamental. El cultivo viral confirmará el diagnóstico y el tratamiento se basará en la administración de aciclovir oral, así como en la adopción de medidas tópicas con baños de asiento y emolientes tópicos ${ }^{2}$. Por otro lado, el VPH también puede producir lesiones vulvovaginales (condiloma acuminado o verrugas genitales). Aunque en niños de dos o tres años de edad las lesiones pueden ser secundarias a transmisión vertical durante el parto vaginal y se han descrito casos de transmi- sión mediante fómites, esta infección también es una enfermedad de transmisión sexual. La biopsia de las lesiones confirmará la presencia del ADN del virus. En un $50 \%$ de los pacientes se ha descrito una resolución espontánea de las lesiones en los cinco años posteriores a su diagnóstico. Si no se opta por una terapia expectante, el tratamiento con láser, el ácido tricloroacético y la crema de imiquimod se han utilizado en estas lesiones ${ }^{18}$.

\section{Cuerpo extraño}

Los cuerpos extraños vaginales en niñas pueden causar vulvovaginitis aguda o crónica. Esta causa flujo vaginal crónico maloliente, y en ocasiones sangrado. Restos de toallitas o papel higiénico son los cuerpos extraños más comúnmente aislados en estas niñas, aunque en ocasiones se encuentran otros objetos como monedas, tapones de botellas o pequeños juguetes ${ }^{8}$. Si el cuerpo extraño es visible y la paciente colabora, se puede extraer por irrigación con agua templada o con ayuda de una cureta plástica, aunque en ocasiones esta maniobra puede requerir sedación para su realización. Asimismo, cuando tratamos a niñas con cuerpos extraños vaginales debemos descartar el abuso sexual como causa de esta entidad. 


\section{Miscelánea}

En raras ocasiones, un flujo vaginal persistente, generalmente asociado a sangrado, puede indicarnos la presencia de un pólipo benigno en la vagina, o lo que es más infrecuente y grave, un tumor maligno (rabdomiosarcoma o sarcoma botrioides) que afecte al himen, a la uretra distal o a la pared anterior de la vagina $^{19}$. En enfermedades sistémicas como la rubéola, la varicela, el sarampión, la escarlatina, la mononucleosis por virus de Epstein-Barr, la enfermedad de Crohn o la de Kawasaki, también pueden presentarse signos y síntomas vulvovaginales como vesículas, fístulas, úlceras o inflamación. Tampoco hay que olvidar que existen malformaciones urinarias, como son el uréter ectópico o el prolapso uretral, que en ocasiones producen irritación vulvar persistente.

\section{Conclusiones}

La mayoría de las vulvovaginitis en la infancia son inespecíficas, y responden bien a tratamientos tópicos locales y medidas higiénicas. Otras bacterias de origen respiratorio o entérico (especialmente $S$. pyogenes y $H$. influenzae) son causas de vulvovaginitis específicas, y su presencia debe investigarse en casos persistentes o refractarios al tratamiento inicial, con recogida de estudios microbiológicos apropiados, pautándose tratamiento antibiótico oral según el germen aislado, sin olvidar que en ocasiones un cuerpo extraño intravaginal puede ser el responsable de la persistencia del cuadro. Por otro lado, algunas enfermedades de transmisión sexual pueden manifestarse con vulvovaginitis en la infancia, y su presencia obligará a descartar abuso sexual en este grupo de niñas.

\section{Bibliografía}

1. Stricker T, Navratil F, Sennhauser FH. Vulvovaginitis in prepubertal girls. Arch Dis Child. 2003;88(4):324-6.

2. Kokotos F, Adam HM. Vulvovaginitis. Pediatr Rev. 2006;27;116-7.

3. Jaquiery A, Stylianopoulos A, Hogg G, Grover $S$. Vulvovaginitis: clinical features, aetiology, and microbiology of the genital tract. Arch Dis Child. 1999;81(1):64-7.

4. Fernández-Cuesta Valcarce MA. Vulvovaginitis (v.2/2008). Guía-ABE. Infecciones en Pedia- tría. Guía rápida para la selección del tratamiento antimicrobiano empírico [en línea] [actualizado el 07/05/2008; consultado el 18/12/2011]. Disponible en www.guia-abe.es

5. Joishy M, Ashtekar CS, Jain A, Gonsalves R. Do we need to treat vulvovaginitis in prepubertal girls? BMJ. 2005;330:186-8.

6. Hill GB, St Claire KK, Gutman LT. Anaerobes predominate among the vaginal microflora of prepubertal girls. Clin Infect Dis. 1995;20(suppl 2):s269-70.

7. Gerstner GJ, Grunberger W, Boschitsch E, Rotter M. Vaginal organisms in prepubertal chil- 
dren with and without vulvovaginitis. A vaginoscopic study. Arch Gynecol. 1982;231:247-52.

8. Jiménez Fernández F, Cermeño PC, Pescador Abad FJ, Ruano Gil M, Mora Guio F, Martín Pérez C. Vulvovaginitis en niñas prepuberales; un estudio preliminar. An Esp Pediatr. 1991;35(5):31921.

9. Sugar NF, Graham EA. Common Gynecologic Problems in Prepubertal Girls. Pediatr Rev. 2006;27:213-23.

10. Paek SC. Pruritus vulvae in prepubertal children. J Am Acad Dermatol. 2001;44:795-802.

11. 11. Pierce $A M$, Hart C. Vulvovaginitis: causes and management. Arch Dis Child. 1992;67: 509-12.

12. Girardet RG, Lahoti S, Howard LA, Fajman NN, Sawyer MK, Driebe EM et al. Epidemiology of sexually transmitted infections in suspected child victims of sexual assault. Pediatrics. 2009; 124(1):79-86.

13. Woods CR. Gonococcal infections in neonates and young children. Semin Pediatr Infect Dis. 2005;16(4):258-70.
14. Goodyear-Smith F. What is the evidence for non-sexual transmission of gonorrhoea in children after the neonatal period? A systematic review. J Forensic Leg Med. 2007;14(8):489-502.

15. Deligeoroglou E, Salakos N, Makrakis E, Chassiakos D, Hassan EA, Christopoulos P. Infections of the lower female genital tract during childhood and adolescence. Clin Exp Obstet Gynecol. 2004;31(3):175-8.

16. Centers for Disease Control and Prevention. Sexually transmitted diseases treatment guidelines 2002. MMWR. 2002;51(RR-6).

17. Lewin LC. Sexually transmitted infections in preadolescent children. J Pediatr Health Care. 2007;21(3):153-61.

18. Syrjänen S. Current concepts on human papillomavirus infections in children. APMIS. 2010;118(6-7):494-509.

19. Solomon LA, Zurawin RK, Edwards CL. Vaginoscopic resection for rhabdomyosarcoma of the vagina: a case report and review of the literature. J Pediatr Adolesc Gynecol. 2003;16(3):13942. 
